\title{
Effect of Friction Fatigue on Pile Capacity in Dense Sand
}

\author{
Kenneth G. Gavin ${ }^{1}$ and Brendan C. O'Kelly ${ }^{2}$
}

\begin{abstract}
The paper presents the results of a series of field tests performed to study the causes of friction fatigue experienced by displacement piles. Four instrumented model piles were installed at a dense sand test-bed site. The test series was designed to impose different levels of cyclic loading during pile installation. Static and cyclic load tests were subsequently performed to study the differences in the axial capacities developed for ostensibly monotonic and cyclic installations. The test results indicated that the mobilized horizontal effective stress regime that controls pile side friction primarily depends on the in situ sand state, as reflected by the cone penetration test (CPT) $q_{c}$ resistance. A zone of highly stressed sand that produced a concentration of high shear resistance was mobilized in the vicinity of the pile base. The horizontal effective stress that acted on the pile shaft reduced in response to cyclic loading, with the largest reductions occurring for high-intensity cyclic loading or when the pile had experienced only a few load cycles during installation. Although cyclic loading caused a reduction in the horizontal effective stress that acted on the pile shaft, the elevated stress built up in the vicinity of the pile base during installation remained higher than that remote from the base. The elevated stress in the vicinity of the pile base only dissipated after cyclic tension loading had been applied.
\end{abstract}

DOI: 10.1061/(ASCE)1090-0241(2007)133:1(63)

CE Database subject headings: Field tests; Models; Friction; Fatigue; Piles; Sand; Displacement.

\section{Background}

The first test that studied the effects of friction fatigue was performed by Vesic (1970), in which the shear stresses mobilized at discrete points along the shaft of a 356-mm-square concrete pile were measured as the pile was driven to $15.25 \mathrm{~m}$ below ground level (bgl) (Fig. 1). Friction fatigue reduced the shear stress mobilized at a given depth in the ground as the distance $(h)$ to the pile base increased. Instrumented pile tests (Lehane 1992; Chow 1997) have shown that the peak shaft resistance $\left(\tau_{f}\right)$ is given by

$$
\begin{gathered}
\tau_{f}=\sigma_{h p}^{\prime} \tan \delta_{f} \\
\sigma_{h p}^{\prime}=\sigma_{h s}^{\prime}+\Delta \sigma_{r d}^{\prime}
\end{gathered}
$$

where $\sigma_{h p}^{\prime}=$ horizontal effective stress at failure, which comprises two components, the stationary horizontal effective stress $\sigma_{h s}^{\prime}$ and a dilation component $\Delta \sigma_{r d}^{\prime}$; and $\delta_{f}=$ interface friction angle.

Boulon and Foray (1986) and others have shown that cavity expansion theory can be used to estimate the increase in the horizontal effective stress due to dilation

$$
\Delta \sigma_{r d}^{\prime}=2 G \delta_{h} / D
$$

where $G=$ shear modulus; $\delta_{h}=$ horizontal displacement of a soil particle at the pile-soil interface; and $D=$ pile diameter.

\footnotetext{
${ }^{1}$ Lecturer, Dept. of Civil Engineering, University College Dublin, Earlsfort Terrace, Dublin 2, Ireland. E-mail: kenneth.gavin@ucd.ie

${ }^{2}$ Lecturer, Dept. of Civil, Structural, and Environmental Engineering, Trinity College Dublin, Dublin, Ireland.

Note. Discussion open until June 1, 2007. Separate discussions must be submitted for individual papers. To extend the closing date by one month, a written request must be filed with the ASCE Managing Editor. The manuscript for this paper was submitted for review and possible publication on March 21, 2006; approved on June 26, 2006. This paper is part of the Journal of Geotechnical and Geoenvironmental Engineering, Vol. 133, No. 1, January 1, 2007. (CASCE, ISSN 1090-0241/2007/1$63-71 / \$ 25.00$.
}

Dilation effects can dominate the shaft capacity for model piles [small values of $D$ in Eq. (3)], although the effects reduce considerably for full-scale piles. Therefore, while quantification of the dilation component is particularly important in the interpretation of model pile test results, prediction of the shaft resistance of full-scale piles requires the accurate determination of $\sigma_{h s}^{\prime}$.

Lehane (1992) reported data from the installation of the steel, closed-ended Imperial College pile $(102 \mathrm{~mm}$ in diameter and $6 \mathrm{~m}$ in length) into a loose-to-medium dense sand deposit at Labenne, in southwest France. The pile was instrumented with horizontal stress sensors at three locations along the pile shaft, which were identified in terms of the distance $(h)$ from the pile base, normalized by the pile diameter $(D)$. The $\sigma_{h s}^{\prime}$ profiles (Fig. 2) closely agreed with the cone penetration test (CPT) end resistance $\left(q_{c}\right)$ profiles, suggesting that $\sigma_{h s}^{\prime}$ was controlled by the in situ sand state. Critically, $\sigma_{h s}^{\prime}$ at a given depth decreased with increasing distance $h$. Chow (1997) reported data from the installation of the same pile in a dense sand deposit at Dunkirk (France) for which the $\sigma_{h s}^{\prime}$ values were 4-5 times greater than the values measured at the Labenne site. The data from both sites indicated that the value of $\sigma_{h s}^{\prime}$ mobilized at a given location along the pile shaft was almost directly proportional to the CPT $q_{c}$ value and depended on the distance $(h)$ of that point above the pile base. Jardine and Chow (1996) and Jardine et al. (2005) proposed the following best-fit relationship (known as the IC design approach):

$$
\sigma_{h s}^{\prime}=0.029 q_{c}\left(\sigma_{v}^{\prime} / P_{\mathrm{atm}}\right)^{0.12}(h / R)^{-0.38}
$$

where $\sigma_{v}^{\prime}=$ vertical effective stress; $P_{\text {atm }}=$ atmospheric pressure; and $R=$ pile radius.

In this expression, $q_{c}$ reflects the combined effects of the soil density and stress level on the value of $\sigma_{h s}^{\prime}$, while the $h / R$ (or $h / D)$ term takes account of the friction fatigue effects. Jardine et al. (2005) suggested that a number of factors contributed to friction fatigue, including: (1) the reduction in horizontal effective stress at a given depth due to migration of the high stress field located about the pile base as the pile was driven past the point 
$\tau_{1}(\mathbf{k P a})$

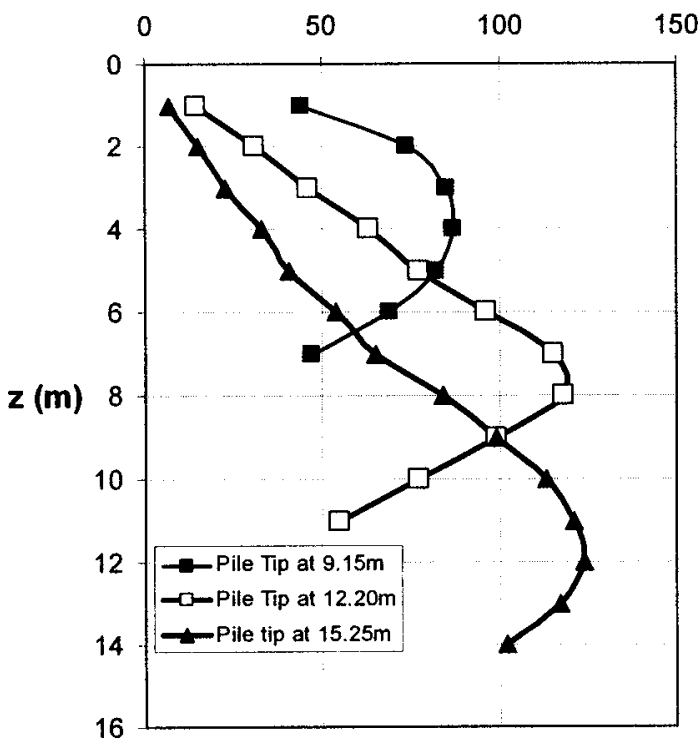

Fig. 1. Profile of shear stress versus depth for $356 \mathrm{~mm}$ square concrete pile [after Vesic (1970)]

under consideration; (2) the effects of cyclic loading during installation; and (3) the creation by circumferential arching of conditions where high radial effective stresses in the ground were prevented from acting on the pile shaft.

The effects of cyclic loading at the pile-soil interface were studied using direct interface-shear tests by Airey et al. (1992), Fioravante (2002), and DeJong et al. (2003). The tests were performed using constant normal stiffness boundary conditions to simulate the stiffness of the ground remote from the pile shaft. As the strains were concentrated in the narrow shear zone adjacent to the pile shaft, the shear stiffness of the unstrained soil outside this shear zone remained at or close to the low-strain $G_{o}$ value. The tests indicated that densification in the shear zone due to cyclic

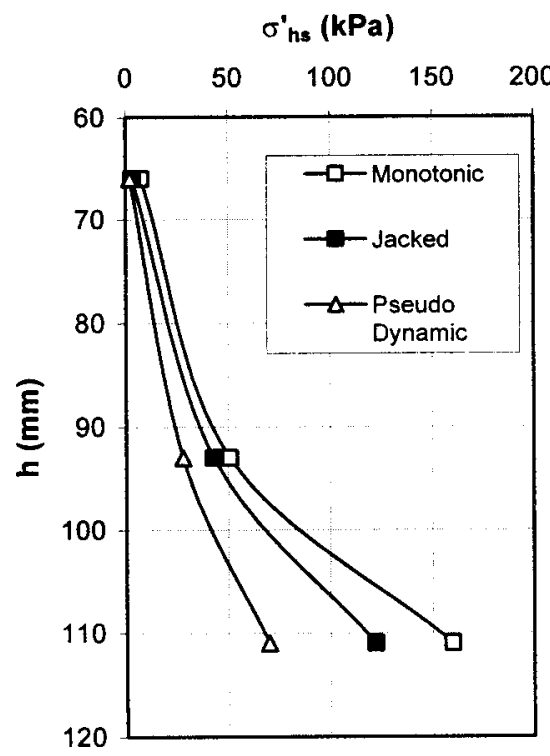

Fig. 3. Effect of installation mode horizontal stress on centrifuge piles [after White and Lehane (2004)]

loading caused a gradual reduction in the normal stress (corresponding to the horizontal effective stress acting on the pile shaft).

White and Lehane (2004) studied the effects of the mode of installation on the shaft resistance of model piles $(9 \mathrm{~mm}$ square in cross section) using a centrifuge. In particular, three different installations were studied: (1) monotonic, in which the piles were continuously pushed to the final depth; (2) jacked, in which the piles were subjected to a number of installation load cycles by pushing downwards $2.0 \mathrm{~mm}$ and subsequently unloading fully; and (3) pseudodynamic in stages, each stage comprising a $2.0 \mathrm{~mm}$ push followed by a $1.5 \mathrm{~mm}$ withdrawal to simulate elastic rebound. The stationary horizontal effective stress $\left(\sigma_{h s}^{\prime}\right)$, measured at three locations along the pile shaft following installation,
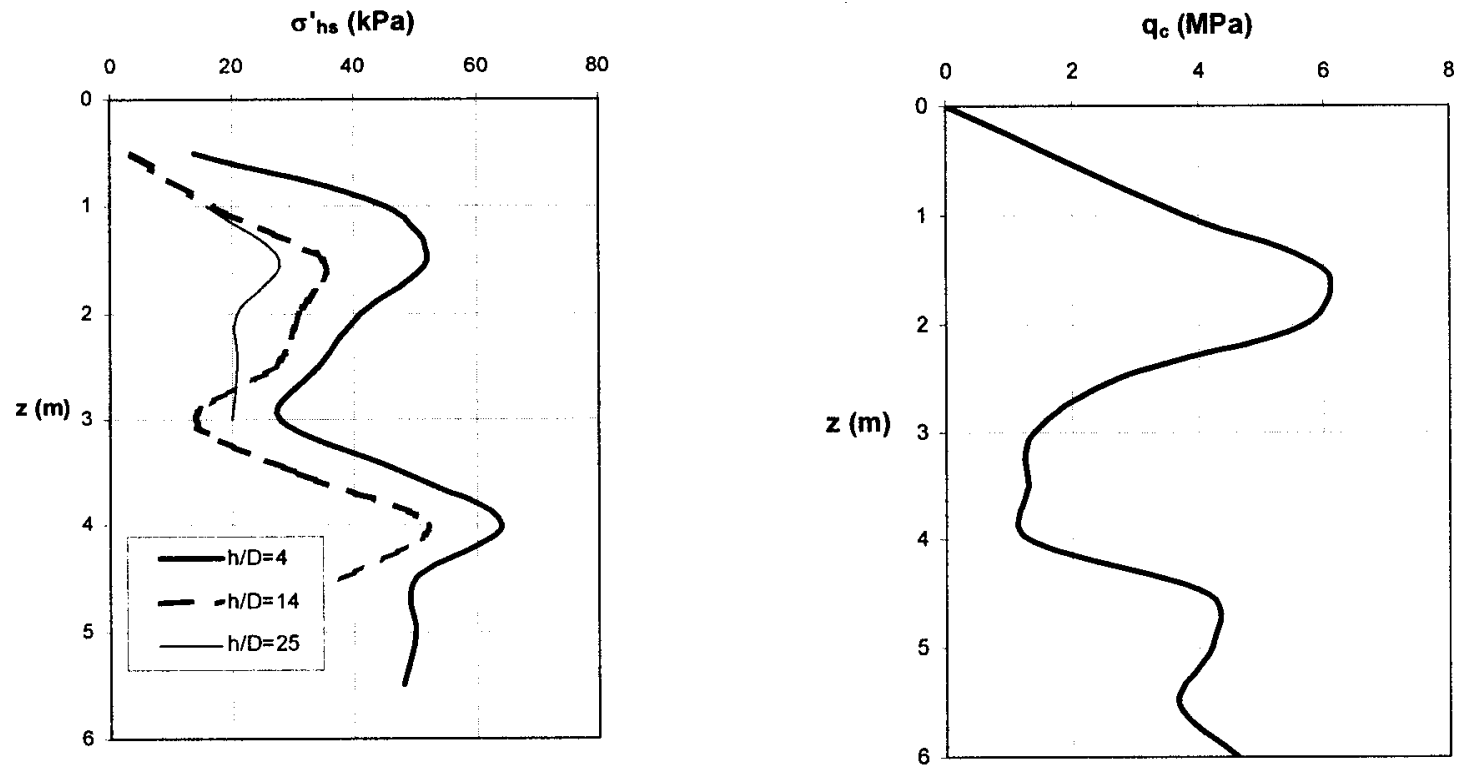

Fig. 2. Profiles of stationary horizontal stress and CPT $q_{c}$ resistance at Labenne [after Lehane (1992)] 

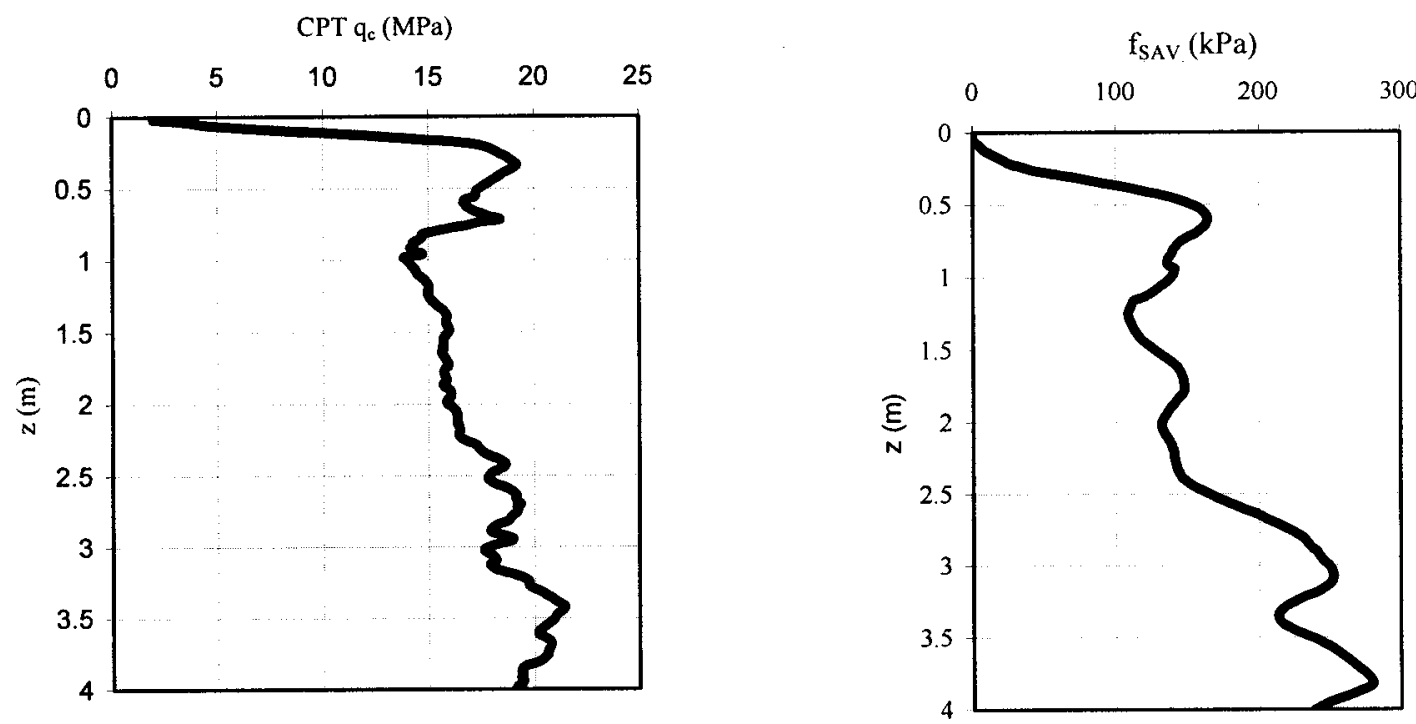

Fig. 4. CPT profiles at Blessington test site

is shown in Fig. 3. The $\sigma_{h s}^{\prime}$ values were greatest for monotonic installation, intermediate for the jacked pile, and lowest for pseudodynamic installation. A key finding was that, unlike the tests reported by Jardine and Chow (1996), the plots of normalized stationary horizontal effective stress $\left(\sigma_{h s}^{\prime} / q_{c}\right)$ versus distance $h$ from the pile base did not produce a unique relationship; rather, the ratio for a given $h$ value depended on the number of load cycles. Using experimental data from the jacked and pseudodynamically installed piles, White and Lehane (2004) argued that the number of load cycles experienced by the soil element rather than the absolute distance of that element from the pile base controlled $\sigma_{h s}^{\prime}$. Field measurements by DeJong and Frost (2002) of the sleeve friction $\left(f_{s}\right)$ acting on a cone penetrometer with multiple friction sleeves appeared to support this hypothesis, with the $f_{s}$ values measured on sleeves located more than three cone diameters from the cone tip being similar. All readings were, however, lower than the sleeve friction measured at the standard location (i.e., near the cone tip).

Despite these findings, a comprehensive review of a large database of instrumented pile tests by Lehane et al. (2005) found that design approaches incorporating $h / D$ rather than the number of load cycles $(N)$ provided better estimates of the side friction for large databases of field tests. Best-fit correlations to the field data were proposed [Eq. (5)] and are known as the University of Western Australia (UWA) design approach (Lehane et al. 2005)

$$
\sigma_{h s}^{\prime}=0.03 q_{c}(h / D)^{-0.5}
$$

The development of high-capacity pile jacking equipment allows the possibility of pile installation with minimal cyclic disturbance. The data in the literature suggests that the side friction of jacked piles may be significantly underestimated if design methods such as the IC and UWA approaches, which incorporate reduction factors for friction fatigue effects, are applied. However, there is little guidance for designers to estimate potential improvements in the capacity of jacked piles. In addition, there appears to be some discrepancy between the physical mechanisms advanced to explain friction fatigue effects for model tests and for full-scale pile behavior. It was in this context that a series of field tests were conducted in dense sand using an instrumented model pile with sensors located at three different levels along the pile shaft. Different installation modes, ranging from monotonic to installations involving large numbers of load cycles, were studied. A number of static and cyclic load tests were also performed to quantify the effects of cyclic loading on the pile capacity.

\section{Description of Experiments}

\section{Site Conditions}

The pile tests were performed in a heavily overconsolidated, glacially derived, very dense, fine sand deposit in Blessington, situated $25 \mathrm{~km}$ southwest of Dublin city. The in situ material had a preconsolidation pressure of about $1.0 \mathrm{MPa}$ and a bulk unit weight of $20 \mathrm{kN} / \mathrm{m}^{3}$, and it was close to $100 \%$ relative density. The ground water table was located at about $6 \mathrm{~m}$ below the piling platform level. The in situ water content was relatively uniform above the groundwater table, ranging between 10 and 12\% (degree of saturation of $71 \%$ ), and did not vary seasonally. The mean particle size $\left(D_{50}\right)$ of the sand was between 0.10 and $0.15 \mathrm{~mm}$.

Eight CPTs were conducted in the area of the pile installations, although two of these tests stopped prematurely on a gravel layer located at about $1.0 \mathrm{~m}$ bgl. Profiles of mean CPT end resistance $\left(q_{c}\right)$ are shown in Fig. 4(a). The $q_{c}$ profiles indicate a variable deposit above $1.0 \mathrm{~m}$ bgl. Below this depth, the $q_{c}$ profiles were reasonably consistent, with values of about $15 \mathrm{MPa}$ for $1.0-2.5 \mathrm{~m} \mathrm{bgl}$, increasing to about $18 \mathrm{MPa}$ at $2.5 \mathrm{~m}$ bgl. The mean sleeve friction $\left(f_{s}\right)$ measured using a friction sleeve located at $h / D=3$ from the cone tip is plotted in Fig. 4(b).

\section{Model Pile}

The stainless-steel model pile was tubular, $73.0 \mathrm{~mm}$ in outer diameter, and closed-ended. Its lower section, $1.7 \mathrm{~m}$ in length, comprised three instrumented units that included total earth-pressure sensors and pore pressure transducers manufactured by Entran Ltd., U.K. The pore pressure transducers, of $3 \mathrm{MPa}$ capacity, were mounted in predrilled holes in the wall thickness of the instrumented units. A porous ceramic disc, $8.5 \mathrm{~mm}$ in diameter and $2.5 \mathrm{~mm}$ in thickness, was mounted flush with the outer wall surface in front of each of the pore pressure transducers. The earthpressure sensors and pore pressure transducers were located 
diametrically apart in the instrumented units at $h / D=1.5,5.5$, and 10.0. Spacer sections, $1.0 \mathrm{~m}$ in length and machined from the same steel pipe, were attached to the top end of the instrumented section, allowing installation of the pile to depths of up to $6 \mathrm{~m}$. Although the pore pressure transducers were installed in the instrumented units during the test program, no excess pore water pressures were recorded at any stage of the tests.

Electrical resistance strain gauges were glued to the inner wall of the pile at the top and bottom of the instrumented section and at the top of all spacer sections. These allowed the distribution of load that acted along the pile and the base load to be determined throughout testing.

\section{Test Program}

The piles were pushed into the dense sand deposit at a rate of $20 \mathrm{~mm} / \mathrm{s}$ using a 20 metric ton capacity CPT truck. The installation loads were measured using a load cell located above the pile head. The load cell and the pile instrumentation were continuously logged at $0.1 \mathrm{~s}$ intervals using a System 5000 data logger throughout the pile installation and load tests. The aim of the work was to study the differences in the behavior of driven and jacked piles. Pile driving was modeled in the tests by applying short jacking strokes using the CPT truck, fully removing the applied load at the end of each stroke, thereby creating a predetermined number of load cycles. Two displacement transducers attached to an independent reference beam monitored the vertical displacement of the pile head during the load tests. Pile installation generally continued until the reaction capacity of the CPT truck was approached, an exception being pile B4, where installation was halted at $2.0 \mathrm{~m} \mathrm{bgl}$ due to the very high horizontal stress that mobilized near the pile base. The need to add spacer sections at stages during monotonic installation to increase the overall length of the pile resulted in periodic unloading for even the ostensibly monotonically installed piles. Full details of the installation procedures (including depths at which the spacer sections were added) and the load tests that were performed are given in Table 1. Schematics of the pile installations showing details of the starter boreholes and the final penetration depths are shown in Fig. 5.

\section{Pile Installation}

\section{Base Resistance}

Typical profiles of the base resistance $\left(q_{b}\right)$ measured during the installation of the monotonically (B2) and cyclically (B3) installed piles are shown in Fig. 6. Pile B2 was installed through a shallower starter borehole, which may explain its relatively high base resistance for shallow penetrations. However, there was no overall systematic variation between the base resistances of either pile and the CPT end resistance value.

\section{Mean Shear Stress}

The mean shear stresses $\left(\tau_{a v}=\right.$ shaft load/shaft area $)$ measured during the installation of piles B1 and B2 are compared in Fig. 7. The applied load at the pile head was fully removed after each $50 \mathrm{~mm}$ drive for pile B1 (cyclic installation). Pile B2 was continuously pushed, and the applied load was only removed twice during its installation at depths of 2.1 and $2.6 \mathrm{~m} \mathrm{bgl}$ to allow the addition of spacer sections to increase the overall pile length.
Table 1. Details of Installation Procedures and Load Tests

\begin{tabular}{|c|c|}
\hline $\begin{array}{l}\text { Pile } \\
\text { number }\end{array}$ & Details \\
\hline \multirow[t]{2}{*}{ B1 } & $\begin{array}{l}\text { Cyclic installation: Load fully removed after every } \\
50 \mathrm{~mm} \text { of pile penetration. }\end{array}$ \\
\hline & $\begin{array}{l}\text { Load tests: Static comp load test at } 2.1 \mathrm{~m} \text { bgl. Cyclic } \\
\text { comp test at } 3.5 \mathrm{~m} \text { bgl. Comprising } 50 \text { load cyles of } \\
50 \mathrm{kN} \text { and } 50 \text { load cycles of } 100 \mathrm{kN} \text {. Static comp } \\
\text { followed by tension load test to failure at } 3.5 \mathrm{~m} \mathrm{bgl} \text {. }\end{array}$ \\
\hline \multirow[t]{2}{*}{$\mathrm{B} 2$} & $\begin{array}{l}\text { Monotonic installation: Pile installed at } 20 \mathrm{~mm} / \mathrm{s} \text {. } \\
\text { Installation halted and load removed at } 2.1 \mathrm{~m} \text { and } \\
2.6 \mathrm{~m} \mathrm{bgl} \text { to allow extra sections to be added. }\end{array}$ \\
\hline & $\begin{array}{l}\text { Load tests: Static comp load test at } 3.5 \mathrm{~m} \mathrm{bgl} \text {. Cyclic } \\
\text { comp test at } 3.5 \mathrm{~m} \text { bgl. Comprising } 50 \text { load cycles of } \\
50 \mathrm{kN} \text { and } 50 \text { load cycles of } 100 \mathrm{kN} \text {. Static tension } \\
\text { followed by comp load test to failure at } 3.5 \mathrm{~m} \mathrm{bgl} \text {. }\end{array}$ \\
\hline \multirow[t]{2}{*}{ B3 } & $\begin{array}{l}\text { Cyclic installation: Load fully removed after every } \\
25 \mathrm{~mm} \text { of pile penetration. }\end{array}$ \\
\hline & Load tests: Static comp load test at $2.8 \mathrm{~m} \mathrm{bgl}$. \\
\hline \multirow[t]{2}{*}{ B4 } & $\begin{array}{l}\text { Monotonic installation: Pile installed at } 20 \mathrm{~mm} / \mathrm{s} \text { to } \\
\text { final penetration depth. }\end{array}$ \\
\hline & $\begin{array}{l}\text { Load tests: Static comp followed by tension load test } \\
\text { to failure at } 2.0 \mathrm{~m} \text { bgl. Cyclic tension test at } 2.0 \mathrm{~m} \\
\text { bgl. Comprising } 50 \text { load cycles of } 10 \mathrm{kN} \text { and } 50 \text { load } \\
\text { cycles of } 20 \mathrm{kN} \text {. Static tension load test to failure at } \\
2.0 \mathrm{~m} \text { bgl. }\end{array}$ \\
\hline
\end{tabular}

The monotonically installed pile B2 (solid symbols, Fig. 7) had a higher side friction than the cyclically installed pile B1. The capacity of pile B2 temporarily dropped immediately after the pile-head load had been removed at 2.1 and $2.6 \mathrm{~m} \mathrm{bgl}$, where the installation was briefly halted. However, the side friction quickly recovered and was typically $40 \%$ greater than that measured for the cyclic installation.

\section{Stationary Horizontal Stress}

In order to understand the side friction response, it was necessary to consider both the stationary and peak horizontal effective stresses (including the dilation component) mobilized at the pilesoil interface. The stationary horizontal effective stress $\left(\sigma_{h s}^{\prime}\right)$ values recorded during monotonic and cyclic installations are shown in Fig. 8 (closed symbols indicating monotonic installation). The stationary $\sigma_{h s}^{\prime}$ values for piles installed by continuous jacking

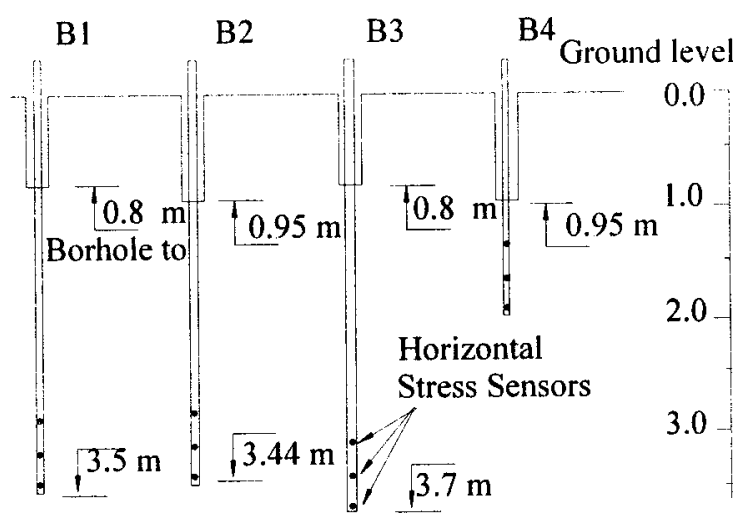

Fig. 5. Details of model pile depths 


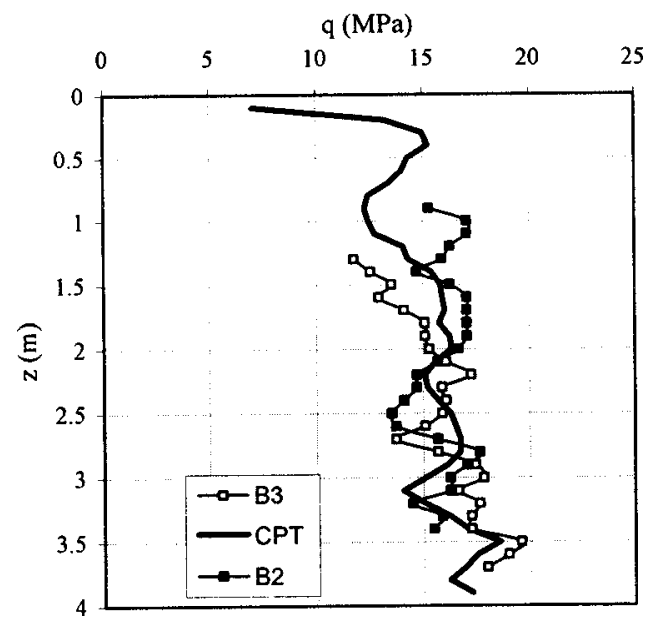

Fig. 6. Base resistance during installation of Piles B2 and B3

could only be measured at the pause periods when the applied load had been fully removed. The following trends were observed:

1. The cyclically installed pile had been pushed from the bottom of a starter borehole, $0.8 \mathrm{~m}$ in depth. The $\sigma_{h s}^{\prime}$ values increased with the penetration depth and became reasonably constant for a given $h / D$ value when the pile had penetrated $1.2 \mathrm{~m}$ below the bottom of the borehole, corresponding to a distance of about 16 pile diameters.

2. A clear $h / D$ trend was evident for the cyclically installed pile with $\sigma_{h s}^{\prime}$ progressively reducing in a given horizon as the pile moved downward.

3. The $\sigma_{h s}^{\prime}$ values were higher for the monotonically installed pile and at a given $h / D$ were at least $50 \%$ higher than those recorded for the cyclic installation.

4. Contrary to the findings of White and Lehane (2004), a clear $h / D$ trend is evident for the monotonic installation, with $\sigma_{h s}^{\prime}$ values for $h / D$ of 5.5 and 10.0 at only 60 and $40 \%$, respec-

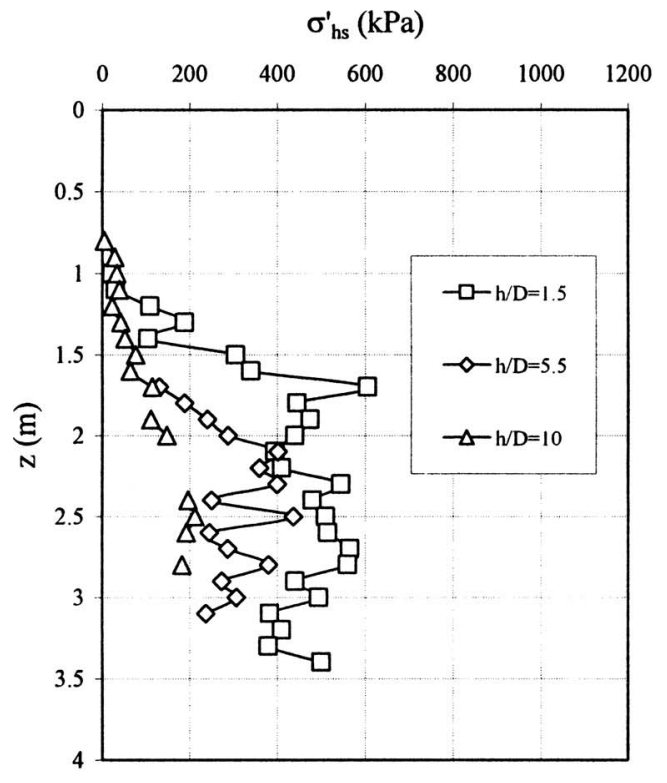

(a)

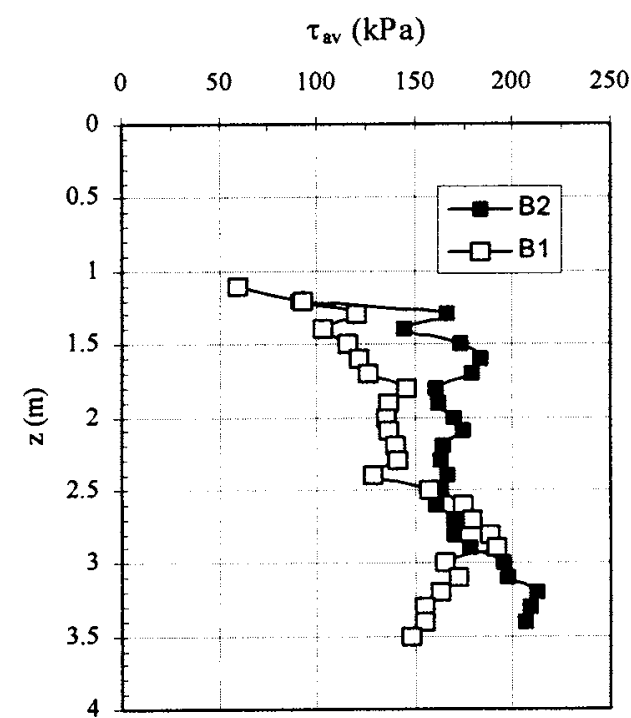

Fig. 7. Average shear stress during installation of Piles B1 and B2

tively, of the values recorded at $h / D=1.5$, despite negligible differences in the $q_{c}$ values over the depth range.

\section{Peak Horizontal Stress}

Although it was noted that full-scale pile behavior is principally controlled by $\sigma_{h s}^{\prime}$, significant dilation during load tests on model piles causes large increases in the horizontal effective stress $\left(\sigma_{h}^{\prime}\right)$, which can dominate the shear stress response. The peak horizontal effective stress $\left(\sigma_{h p}^{\prime}\right)$ profiles for the monotonic and cyclic installations, including the numbers of load cycles experienced by the sensors, are given in Fig. 9:

1. In common with the $\sigma_{h s}^{\prime}$ values for cyclic installation, the $\sigma_{h p}^{\prime}$ values measured for both piles increased with depth and became roughly constant for a given $h / D$ value when the pile

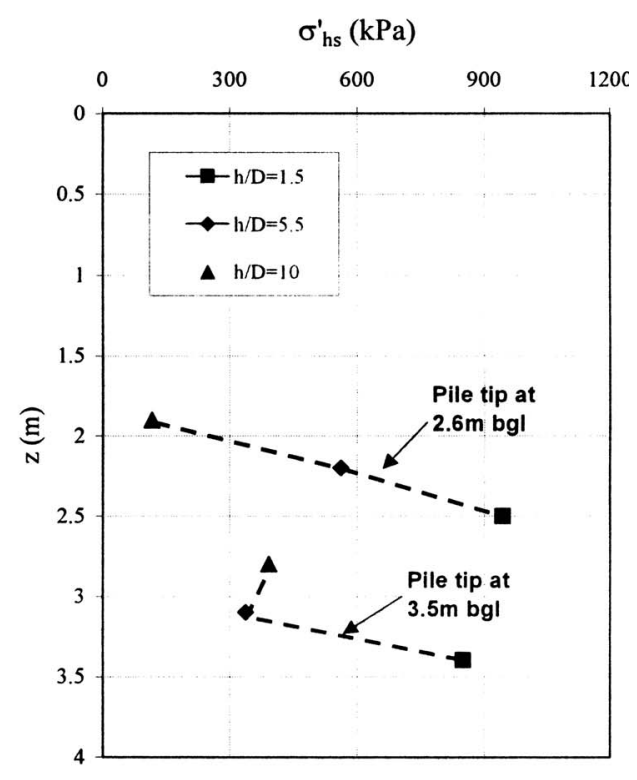

(b)

Fig. 8. Stationary horizontal stress acting on (a) cyclically; (b) monotonically installed piles 


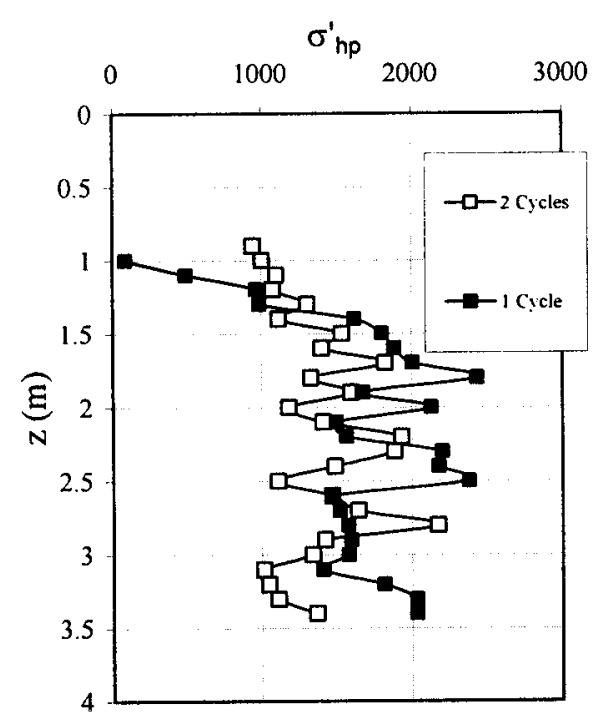

(a)

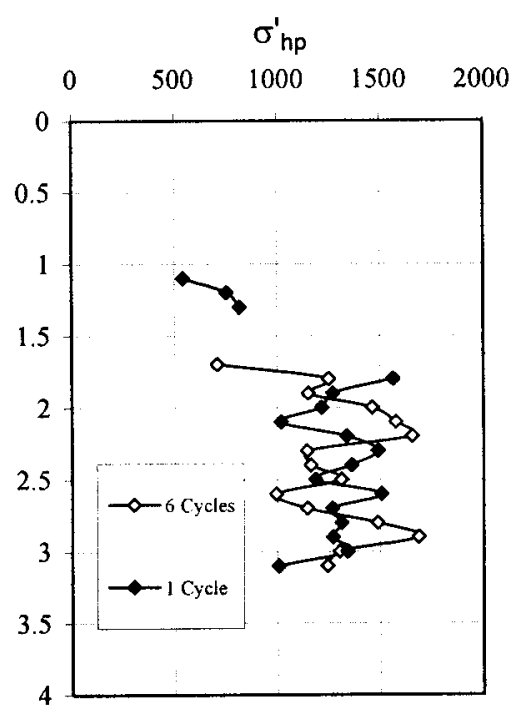

(b)

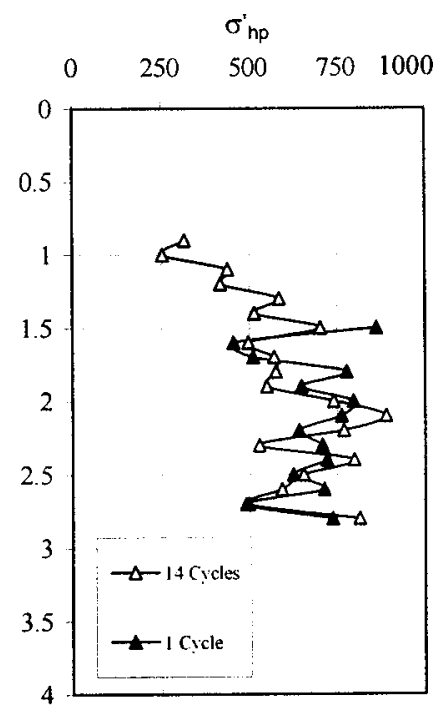

(c)

Fig. 9. Peak horizontal stress during installation of monotonic and cyclically installed piles: (a) $h / D=1.5$; (b) $h / D=5.5$; and (c) $h / D=10$

had penetrated $1.2 \mathrm{~m}$, corresponding to a distance of about 16 pile diameters.

2. The $\sigma_{h p}^{\prime}$ values were three to four times greater than the corresponding stationary values, indicating that the dilationinduced stress increases had been greatest remote from the pile base.

3. Although there was a trend for the $\sigma_{h p}^{\prime}$ values to reduce with increasing $h / D$, the measured values for both piles were remarkably similar (apart from the sensor at $h / D=1.5$ ), suggesting that the $\sigma_{h p}^{\prime}$ values at locations further away from the pile base were independent of the number of installation load cycles.

4. In general, the $\sigma_{h p}^{\prime}$ values measured at $h / D=1.5$ were greater for the ostensibly monotonically installed pile (closed symbols) that experienced a single load cycle during installation. However, the monotonically installed $\sigma_{h p}^{\prime}$ values were similar to those recorded for cyclic installation, when just a single load cycle had been experienced at, for example, 2.1 or $2.6 \mathrm{~m} \mathrm{bgl}$.

In summary, the $\sigma_{h p}^{\prime}$ values were greatest near the pile base and reduced with increasing $h / D$. The $\sigma_{h p}^{\prime}$ values were equal at a given location along the pile shaft for two or more load cycles. Significant differences in the stationary horizontal effective stresses, which control the shaft capacity of full-scale piles, were evident for the monotonic and cyclic installations. However, during loading these differences were partially masked by dilation along much of the shaft of the small diameter model pile.

\section{Load Tests}

A series of static load tests were performed on the piles at the final penetration depths and also in some cases at intermediate depths. In general, a static compression load test was performed to establish the axial capacity of the pile, which was then followed by a one-way compression or cyclic tension load test. The cyclic tests were load-controlled, in which two batches of 50 load cycles representing 33 and $66 \%$ of the axial capacity were ap- plied. Static tension load tests usually completed the test regime. Full details of the sequence of loads that were applied to the piles are given in Table 1.

\section{Static Load Tests}

Given the high side friction resistance during installation, it was perhaps unsurprising that the monotonically installed piles exhibited greater capacities for the first-time load tests than the cyclically installed piles. The load-displacement responses measured during the static load tests performed at $3.5 \mathrm{~m} \mathrm{bgl}$ on the monotonically installed pile (B2) and cyclically installed pile (B1) are compared in Fig. 10(a). Pile B2 showed a stiffer response and had a higher ultimate resistance, defined herein as the load at which plunging failure occurred (at which the pile displacement increased under a constant applied load). The unit base resistance that were mobilized during the load tests were calculated to allow direct comparison of the behavior of piles with different final penetration depths. Fig. 10 shows the normalized base resistance $\left(q_{b} / q_{c}\right)$ mobilized during the static load tests for both the monotonic and cyclic installations. The initial value of the residual base pressure was greater for the cyclically installed pile (B3), due to its greater penetration. However, both piles displayed similar stiffness responses, with end-bearing stresses of $90-95 \%$ of the measured $q_{c}$ values for $h / D \cong 0.05$ (pile penetration of $4 \mathrm{~mm}$ ) with the base resistance equaling the measured $q_{c}$ values for $h / D \geqslant 0.20$ (pile penetrations $\geqslant 15 \mathrm{~mm}$ ).

Therefore, the differences in the axial load capacities of the piles must have occurred due to the higher side friction resistance that was mobilized during monotonic installation. A feature of all the first-time compression load tests was that, despite the large vertical displacements (typically $50 \%$ of pile diameter), the total pile resistance mobilized was always lower than the applied load during pile installation. The ratio of the load measured during the static load tests $\left(Q_{S T}\right)$ to that applied during pile installation $\left(Q_{I N}\right)$ appeared to be independent of the installation mode and, based on the small number of tests performed, ranged between 70 and $80 \%$. Given that the base resistance values measured during both 


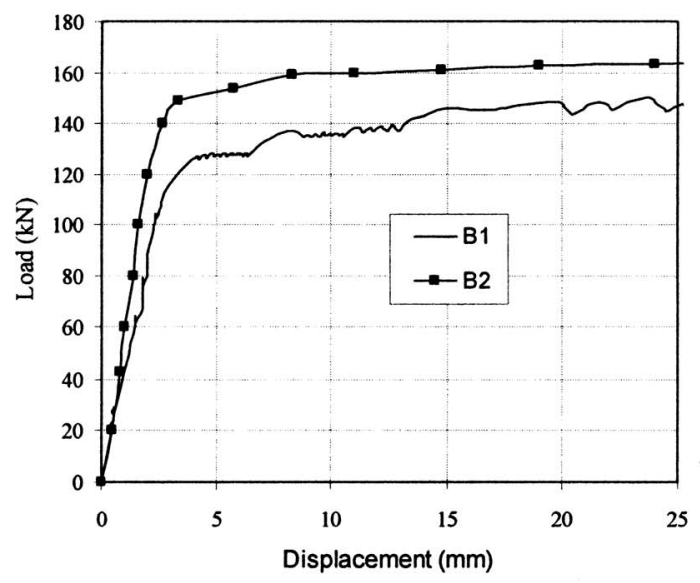

(a)

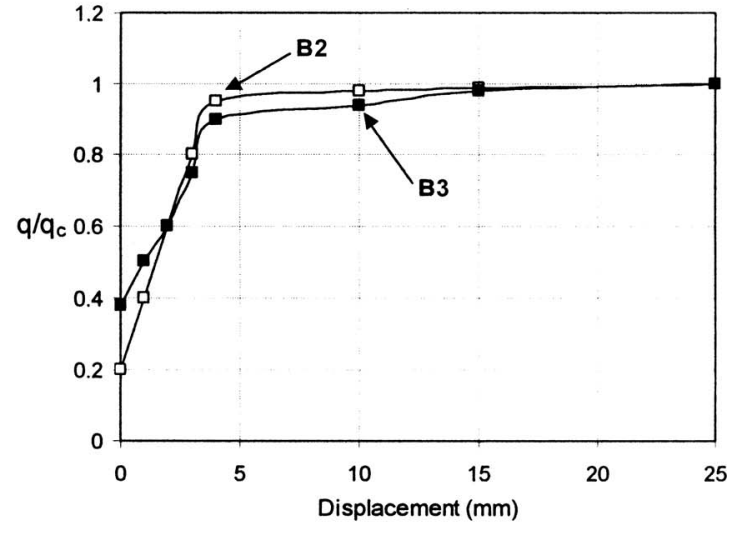

(b)

Fig. 10. (a) Load-displacement response of Piles B1 and B2 measured at $3.5 \mathrm{~m} \mathrm{bgl}$; (b) mobilization of base resistance during static load tests on piles $\mathrm{B} 2$ and $\mathrm{B} 3$

installation and the static load tests were similar, the reduction in ultimate pile capacity can only be explained by the reductions in the side friction resistance. As the side friction resistance of the model piles was controlled by $\sigma_{h p}^{\prime}$, the changes in this value between pile installation and subsequent loading were studied.

The $\sigma_{h p}^{\prime}$ profiles at the end of pile installation were compared with those measured during subsequent load tests for the monotonic (closed symbols) and cyclic installations (open symbols) in Fig. 11. The numbers of load cycles experienced by the sensors are also shown in brackets in Fig. 11. The data provided the following insights into the degradation of the shaft resistance:

1. The $\sigma_{h p}^{\prime}$ values at $h / D=1.5$ were significantly greater than the values measured with increasing distance from the pile base $(h / D=5.5$ or 10.0$)$ for monotonic installation.

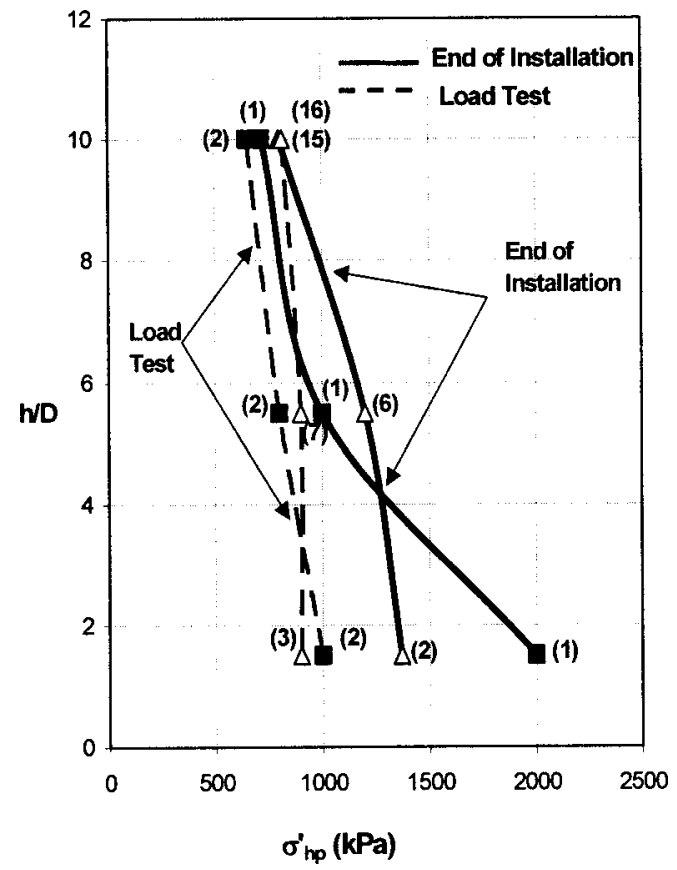

Fig. 11. Variation of peak horizontal stress from end of installation to first static load test
2. The $\sigma_{h p}^{\prime}$ values reduced for all $h / D$ during static loading. The greatest reductions were measured at $h / D=1.5$, namely, a $50 \%$ decrease in the installation value for the monotonically installed pile and a $34 \%$ decrease in the installation value for the cyclically installed pile.

3. The reductions in $\sigma_{h p}^{\prime}$ at $h / D=5.5$ and 10.0 were much lower and the rate of reduction appeared to decrease as the number of load cycles increased.

4. The $\sigma_{h p}^{\prime}$ profiles for the monotonically installed piles and the CPT $q_{c}$ data [Fig. 4(a)] indicate a tendency for the peak side friction resistance to be higher near the pile base and roughly equal along the remainder of the pile shaft. However, the application of a single load cycle reduced the positive effect of high stress on the shaft resistance near the pile base and resulted in a relatively uniform profile of peak side friction resistance along the entire pile shaft.

\section{Cyclic Load Tests}

The test regime of cyclic loading was chosen to examine the behavior of the piles at typical working loads of between onethird and two-thirds of the ultimate capacity. Although detailed consideration of the cyclic load tests is beyond the scope of this paper (Chatta 2006), this load level was not sufficient to mobilize the peak shaft resistance so the variation in the peak horizontal stress could not be determined. Nevertheless, the effects of cyclic loading on the stationary horizontal effective stress were studied, because this parameter controls full-scale pile behavior. The $\sigma_{h s}^{\prime}$ values for $h / D=1.5,5.5$, and 10.0 are shown in Fig. 12. Only the data for the lowermost sensor $(h / D=1.5)$, which had penetrated greater than the critical depth of 16 pile diameters, is shown for pile B4, because its installation had been prematurely halted. For the monotonically installed pile B4 [solid triangles, Fig. 12(a)], the $\sigma_{h s}^{\prime}$ values rapidly reduced from 1,050 to $950 \mathrm{kPa}$ immediately after installation and reduced further to $650 \mathrm{kPa}$ at the end of the static load tests. Similar large reductions in the initial $\sigma_{h s}^{\prime}$ value were measured for pile B2, such that the $\sigma_{h s}^{\prime}$ value measured at $h / D=1.5$ at the end of the third load cycle was only slightly greater than that for cyclic installation (B1).

Low-level cyclic loading was performed at one-third of the pile capacity and comprised 50 compression load cycles of $50 \mathrm{kN}$ 


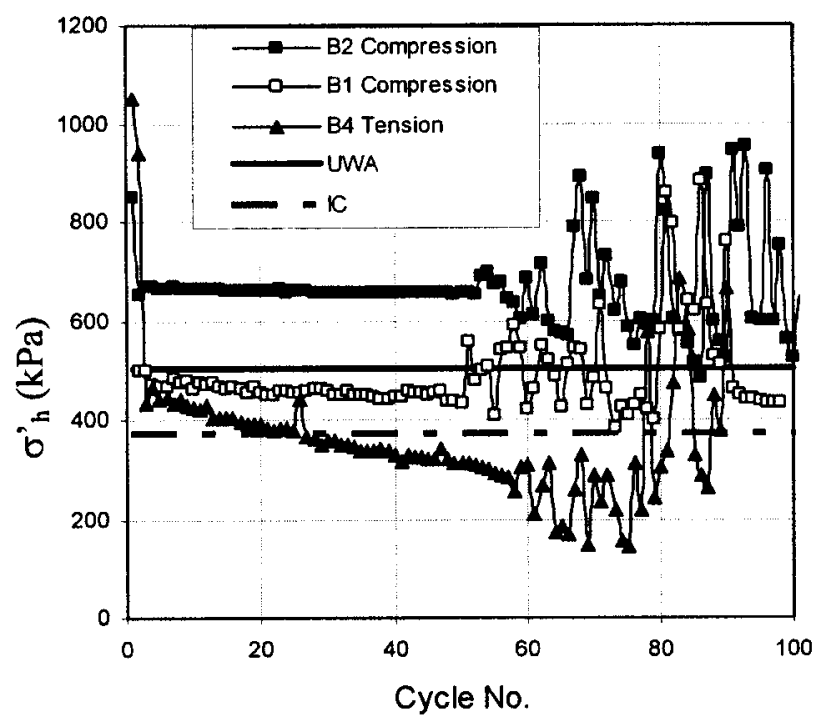

(a)

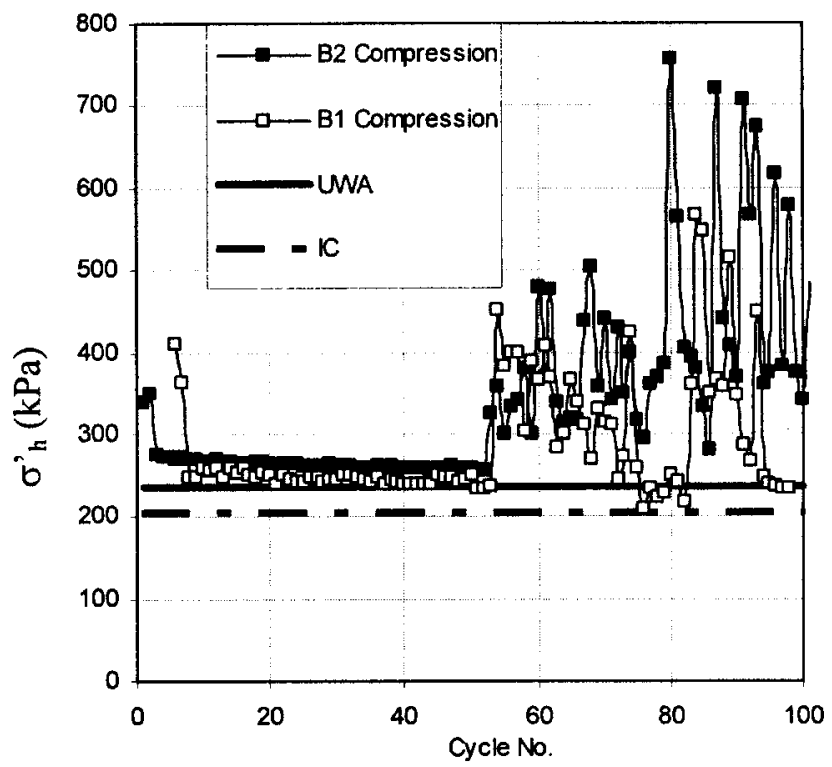

(b)

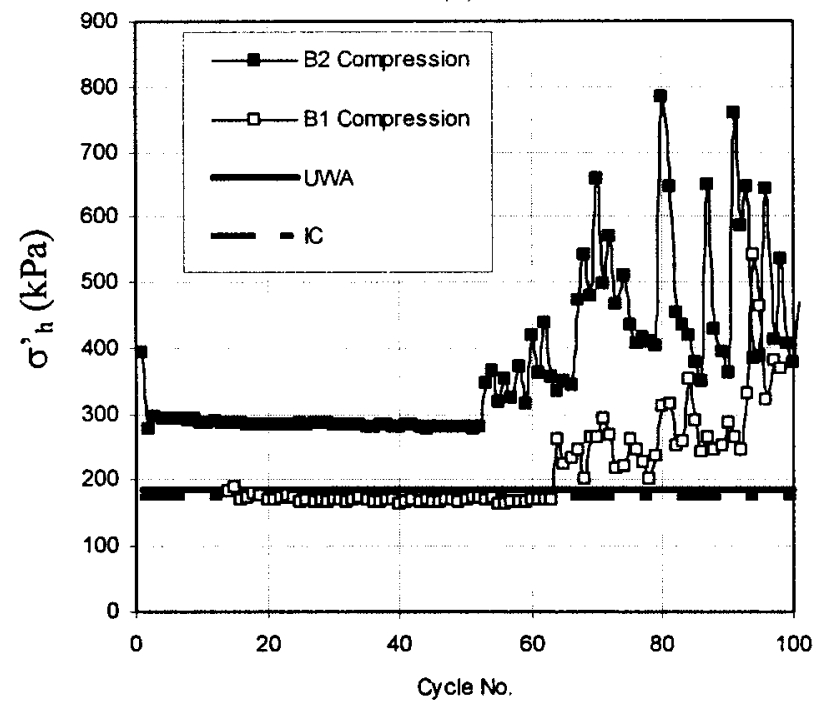

(c)

Fig. 12. Effect of cyclic loading on stationary horizontal stress: (a) $h / D=1.5$; (b) $h / D=5.5$; and (c) $h / D=10$ for piles B1 and B2 and 50 tension load cycles of $10 \mathrm{kN}$ for pile B4. During compression cyclic loading, the $\sigma_{h s}^{\prime}$ values reduced only slightly, as very little side friction resistance had been mobilized due to the high residual base resistance of up to $40 \mathrm{kN}$ under the applied pile-head load of $50 \mathrm{kN}$. In contrast, cyclic tension loading reduced the locked-in base pressures and decreased $\sigma_{h s}^{\prime}$ in the vicinity of the pile base.

High-level cyclic loading (cycle numbers 50-100) caused large reductions in the $\sigma_{h s}^{\prime}$ values measured for the monotonically installed piles B2 and B4 at $h / D=1.5$. In the case of pile B2, the applied pile-head load of $100 \mathrm{kN}$ was significantly greater than the $50-60 \mathrm{kN}$ ultimate base resistance, so a significant proportion of the side friction resistance had been mobilized. Although there is some scatter in the $\sigma_{h s}^{\prime}$ values measured at $h / D=1.5$ for pile $\mathrm{B} 1$, the values at the end of high-level cycling remained largely unchanged from the initial values throughout the loading sequence. The $\sigma_{h s}^{\prime}$ values at $h / D=1.5$ for both compression piles were very similar after 14 cycles at the higher load level. The IC and UWA design approaches [Eqs. (4) and (5)] both provided reasonable estimates of the measured $\sigma_{h s}^{\prime}$ values. The $\sigma_{h s}^{\prime}$ values acting on the pile in tension loading were about $33 \%$ of those that acting on the compression piles. Greater scatter occurred in the $\sigma_{h s}^{\prime}$ measurements for monotonic installation with increasing numbers of load cycles $[N>64$; Fig. 12(a)]. Although there was a trend for the piles tested in compression to achieve residual $\sigma_{h s}^{\prime}$ values (intermediate of the estimates given by the IC and UWA design approaches), large increases in the $\sigma_{h s}^{\prime}$ values occasionally occurred accompanied by large pile settlement. However, the recovery in the $\sigma_{h s}^{\prime}$ values was temporary and the values quickly reduced to residual levels following a small number of additional load cycles, at which point further pile settlement occurred.

In general, the level of $\sigma_{h s}^{\prime}$ acting further from the pile base increased in magnitude during cyclic loading for both the monotonically and cyclically installed piles [Figs. 12(b and c)]. The $\sigma_{h s}^{\prime}$ values at these locations were much closer after only a relatively small number of load cycles [Figs. 12(b and c)] and did not vary much from the residual levels, even after a large number of load cycles had been applied. Again, the IC and UWA design approaches both accurately predicted the $\sigma_{h s}^{\prime}$ values measured after a small number of load cycles.

\section{Conclusions}

Cyclic loading had no effect on the base resistance or base stiffness of the displacement piles that were installed in dense sand. In contrast, the side friction resistance of ostensibly monotonically installed piles was significantly greater than that for cyclic installation.

The following conclusions are made in relation to the stationary horizontal effective stress $\left(\sigma_{h s}^{\prime}\right)$ that controls the side friction resistance:

1. The $\sigma_{h s}^{\prime}$ values that were mobilized during pile installation were greatest for monotonic installation and were dependent on the CPT end resistance, the $h / D$ ratio, and the number of load cycles.

2. The highest $\sigma_{h s}^{\prime}$ values were mobilized in the vicinity of the pile base and reduced with increasing distance away from the pile base, regardless of the mode of installation.

3. The $\sigma_{h s}^{\prime}$ values reduced during load cycling, with the greatest reduction occurring during the initial load cycles and at higher cyclic load levels. 
4. Although the levels of $\sigma_{h s}^{\prime}$ acting on the monotonically installed piles were initially much higher than those recorded for the cyclically installed piles, the values were indistinguishable after the application of a relatively small number of working load cycles.

An $h / D$ trend whereby the stresses were elevated in the vicinity of the pile base was evident even after cyclic compression loading. However, the trend disappeared during cyclic tension loading, suggesting that the effect arises, at least in part, due to the presence of high residual stress built up near the pile base during installation.

The significance of these observations is that, although the shaft resistance of jacked piles may be greater than that of driven piles, a small number of load cycles are sufficient to remove any enhancement in the horizontal stress regime that was gained as a result of monotonic installation. This explains the relatively good performance of existing design approaches that do not explicitly account for cyclic loading effects in their formulation.

The data from the model piles were strongly influenced by dilation during loading. Erroneous conclusions would arise, particularly in relation to $h / D$ trends under both monotonic and cyclic loading, if the dilation effects were not taken into account in the analysis.

\section{Acknowledgments}

The writers wish to thank the following people for significant contributions to the work described: Mr. Irfan Chatta, former research student at University College Dublin, who performed the site testing; David Gallagher and Frank Dillon, who designed and built the instrumented pile; the technical staff at University College Dublin and Trinity College Dublin, including George Cosgrave, David McCauley, Martin Carney, and George Jones, who assisted in the fieldwork; and Roadstone Ltd., for permission to use the quarry at Blessington, County Wicklow.

\section{Notation}

The following symbols are used in this paper:

$D=$ outer pile diameter;

$f_{s}=$ friction sleeve resistance measured during cone penetration test;

$G=$ shear modulus of soil;

$G_{o}=$ small strain modulus of soil;

$h=$ height above pile tip;

$N=$ number of load cycles;

$P_{\text {atm }}=$ atmospheric pressure;

$Q_{I N}=$ pile resistance during installation;

$Q_{S T}=$ pile resistance during static load test;

$q_{b}=$ total end bearing resistance; $q_{c}=$ end bearing resistance measured during cone penetration test;

$R=$ outer pile radius;

$\alpha=$ a reduction factor applied to $q_{c}$ when estimating end bearing;

$\Delta \sigma_{h}^{\prime}=$ increase in horizontal effective stress during pile loading;

$\delta_{f}=$ interface friction angle at failure;

$\delta_{h}=$ horizontal displacement of soil particle at pile-soil interface;

$\sigma_{h}^{\prime}=$ horizontal effective stress;

$\sigma_{h p}^{\prime}=$ horizontal effective stress at peak shear stress;

$\sigma_{h s}^{\prime}=$ horizontal effective stress measured when pile is stationary;

$\sigma_{v}^{\prime}=$ vertical effective stress;

$\tau_{a v}=$ average shear stress acting on pile shaft; and

$\tau_{f}=$ peak local shear stress.

\section{References}

Airey, D. W., Al-Douri, R., and Poulos, H. G. (1992). "Estimation of pile friction degradation from shear box tests." Geotech. Test. J., 15(4), 388-392.

Boulon, M., and Foray, P. (1986). "Physical and numerical simulation of lateral shaft friction along offshore piles in sand." Proc., 3rd Int. Conf. on Numerical Methods in Offshore Piling, Institut Francais du Petrol, Nantes, France, 127-147.

Chatta, I. (2006). "Investigation of installation effects and cyclic loading on piles in sand." MS thesis, University College, Dublin, U.K.

Chow, F. (1997). "Investigations into the behavior of displacement piles for offshore structures." Ph.D. thesis, University of London (Imperial College), London.

DeJong, J. T., and Frost, J. D. (2002). "A multi-friction sleeve attachment for the cone penetrometer." Geotech. Test. J., 25(2), 111-127.

DeJong, J. T., Randolph, M. F., and White, D. J. (2003). "Interface load transfer degradation during cyclic load: A microscale investigation." Soils Found., 43(4), 81-93.

Fioravante, V. (2002). "On the shaft friction modelling of nondisplacement piles in sand." Soils Found., 42(2), 23-33.

Jardine, R. J., and Chow, F. C. (1996). "New design methods for offshore piles." Publication No. 96/103, Marine Technology Department, London.

Jardine, R. J., Chow, F. C., Overy, R., and Standing, J. (2005). ICP design methods for driven piles in sands and clays, Thomas Telford, London.

Lehane, B. M. (1992). "Experimental investigations of pile behavior using instrumented field piles." Ph.D. thesis, University of London (Imperial College), London.

Lehane, B. M., Scheider, J. A., and Xu, X. (2005). "CPT based design of driven piles in sand for offshore structures." Internal Rep. No. GEO:05345, University of Western Australia, Perth, Australia.

Vesic, A. S. (1970). "Tests on instrumented piles, Ogeechee River site." $J$. Soil Mech. and Found. Div., 96(2), 561-584.

White, D. J., and Lehane, B. M. (2004). "Friction fatigue on displacement piles in sand." Geotechnique, 54(10), 645-658. 